\title{
Monitoring Plan on PCDD/Fs and DL-PCBs Milk Contamination in Campania Region
} (Italy)

\author{
Francesco Paolo Serpe, Alfredo Scaramuzzo, Pasquale Maglio, Sara Lambiase, \\ Mauro Esposito \\ Istituto Zooprofilattico Sperimentale del Mezzogiorno, Portici, Italy \\ Email: francesco.serpe@izsmportici.it
}

Received 3 July 2015; accepted 28 July 2015; published 31 July 2015

Copyright (C) 2015 by authors and Scientific Research Publishing Inc. This work is licensed under the Creative Commons Attribution International License (CC BY). http://creativecommons.org/licenses/by/4.0/

(c) (i) Open Access

\begin{abstract}
During the carrying out of the monitoring plan as part of the Regional Law n. 3/2005 emerged, in 2008, the well known "buffalo milk crisis" that led to the enactment of other monitoring plans targeted to the research of dioxins in food. From the last monitoring plan on PCDD/Fs and DL-PCBs in Campania Region, named as "Surveillance plan 2011-2014", all dairy products from N. 50 farms intended to the production of bovine, buffalo and ovine milk, resulted compliant to the maximum levels fixed by EU in Regulation 1259/2011, suggesting the effectiveness of the restrictive measures on farming practices applied after the sanitary emergency of 2008 . On the other hand, the action limits reported in EU Recommendations 516/2011 and 711/2013 were exceeded in two sheep farms and two buffalo farms, to represent the critical issues that nowadays exist.
\end{abstract}

\section{Keywords}

Dioxin, Campania Region Italy, Milk

\section{Introduction}

The PCDD/Fs are a group of 75 polychlorinated dibenzo-p-dioxins and 135 polychlorinated dibenzofurans, belonging to the group of human endocrine disruptor. Dioxin-like PCBs are a class of 12 polychlorinated biphenyls having chemical and toxicological properties comparable to those of the PCDD/Fs. PCDD/Fs are unwanted by-products of several processes, whereas PCBs were intentionally produced; both are chemically inert and resistant to biodegradation; therefore they are extremely persistent in the environment. Furthermore they are lipophilic compounds then they accumulate in fat tissues and along the food chain. 
Industrial processes as metallurgical production, paper making, manufacturing of chlorinated pesticides, above all waste combustion, originate dioxins, as is well known. In the past early years, in Campania Region Italy, the entry into food chain of dioxins was mainly linked to bad farming practices consisting in exposition of feed self-produced to fumes of illegal burning of wastes, whereas the industrial contribution on presence of dioxins was not relevant in this region [1]-[3].

The concern about dioxins contamination in Campania Region began in 2001, during the execution of National Residue Plan (PNR), when two sheep milk samples resulted non-compliant with ex Reg. 2375/01/CE; other emergencies were registered during the execution of plans such as the regional plans in 2003 [1]-[3] and 2007 (surveillance plan) and the ministerial extra-PNR plan in 2007. The well known "buffalo milk crisis" emerged in 2008 during the carrying out of the monitoring plan as part of the Regional Law n. 3/2005 (aimed to the screening of several environmental pollutants in food, including dioxins) and led to the enactment of an EU-Ministry of health extraordinary plan in the period 2008-2009 that was targeted to the research of dioxins in food. From this plan, several farms resulted contaminated, although the application of suitable restrictive measures led the farmers to decontaminate the animals. The monitoring plan on PCDD/Fs and DL-PCBs contamination in Campania Region of 2011, whose data are presented in this work, fits into this context of sanitary emergencies.

\section{Experimental}

\subsection{Chemical and Reagents}

Certified standards solutions of PCDD/Fs and PCBs were provided by CIL (Cambridge Isotope Laboraries Inc, Tewksbury, Massachusetts, USA). Solvents were purchased by LGC Standards (Teddington, Middlesex, UK); purity of all solvents was for trace analysis (pico-grade). Water was purified using a Milli-Q system (Merck Millipore Corporation, Darmstadt, Germany).

\subsection{Sampling}

On the basis of the risk assessment from data on farm hygiene and environment, $n$. 50 farms in risk areas were identified. The farms were intended to the production of bovine (n. 17), buffalo (n. 29) and ovine (n. 4) milk. Samples were collected by veterinary authorities according to ex EC Reg. 252/2012, avoiding any possible source of contamination by dioxins and PCBs; 5 aliquots of $1 \mathrm{~kg}$ each per sample were sent to the laboratories of Istituto Zooprofilattico Sperimentale del Lazio e della Toscana (IZSLT) and Istituto Zooprofilattico Sperimentale del Mezzogiorno (IZSM), recommended by the European Commission, working in conformity with ex Reg. CE 1883/2006.

\subsection{Sample Preparation}

Samples were extracted by Soxhlet (IZSLT) or accelerated solvent extractor (IZSM) Thermo Fisher Scientific ASE 350 (Thermo Fisher Scientific Inc, Waltham, Massachusetts, USA), using a mixture acetone:hexane (1:4 $\mathrm{v} / \mathrm{v}$ ); solvent volume was $150 \mathrm{~mL}$ and in the range of $100-200 \mathrm{~mL}$ respectively. The clean-up consisted of multi-step column chromatography (acid-basic silica/alumina/carbon) carried out by a Power prep ${ }^{\mathrm{TM}}$ system (Fluid Management System Inc, Watertown, Massachusetts, USA).

\subsection{Instrumentation}

Analysis was performed on Thermo Fisher Scientific MAT 95 HRGC/HRMS, during the first period of monitoring plan (IZSLT), and, further, Thermo Fisher Scientific DFS HRGC/HRMS (IZSM) both at a mass resolution of $\mathrm{R}$ at minimum of 10,000 by isotope dilution with every analysed compound (the exception being $1,2,3$, 7, 8, 9-HxCDD) having its own ${ }^{13} \mathrm{C}_{12}$-labelled internal quantification standard added to the sample before extraction, according to US-EPA method 1613b [4]. The fat percentage and concentration of each congener, expressed as World Health Organization toxic equivalent quantity (WHO-TEQ) pg/g fat in agreement with the Regulation EC 1259/2011, was determined for each sample.

\section{Results and Discussion}

The total PCDD/Fs concentration is expressed as the sum of TEQs of 17 polychloro substituted furans and di- 
oxins congeners, and the total concentration of dl-PCBs is expressed as the sum of TEQs of twelve congeners, using TEFs 2005 [5], according to EU Reg. 1259/2011.

All the farms controlled during the monitoring plan resulted compliant to the maximum levels reported in the EU Reg. 1259/2011 (2.5 pg/g fat WHO-TEQ for dioxins and furans and 5.5 pg/g fat WHO-TEQ for the sum dioxins, furans and DL-PCBs), and to the action limits reported in ex EU Rec. 516/2011 and EU Rec. 711/2013 $(1.75 \mathrm{pg} / \mathrm{g}$ fat WHO-TEQ for dioxins and furans and $2.0 \mathrm{pg} / \mathrm{g}$ fat WHO-TEQ for DL-PCBs) except two sheep farms that presented, respectively, a milk content of PCDD/Fs-DL-PCBs-SUM exceeding to the maximum limits and levels of DL-PCBs exceeding the action limit, and two buffalo farms that presented levels of PCDD/Fs exceeding the action limit.

The concluding results are summarized in Figures 1-4, in which box plots of the global data from 2011-2014 monitoring plan, divided per congeners groups and species, are shown. In Figures 2-4 maximum limits and action limits are indicated by horizontal lines and in all figures dots evidence the values laying in the $4^{\text {th }}$ quartile (outliers) of the distributions, representing the samples to major risk of non compliance to the maximum limits.

In Table 1, a comparison between the medians from I, III and VI semesters of the 2011-2014 monitoring plan and the medians from the Regional Surveillance plan of 2007 (unpublished data) is reported; it should be noted

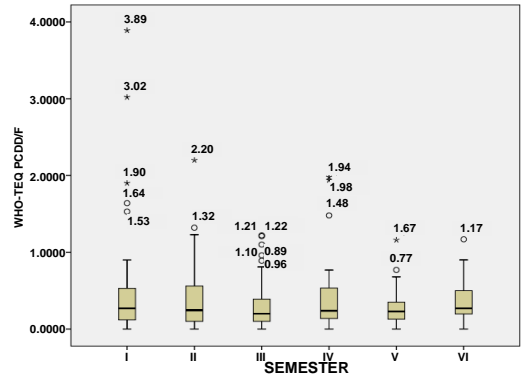

(a)

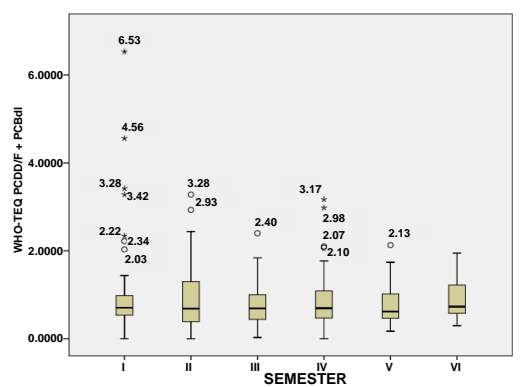

(b)

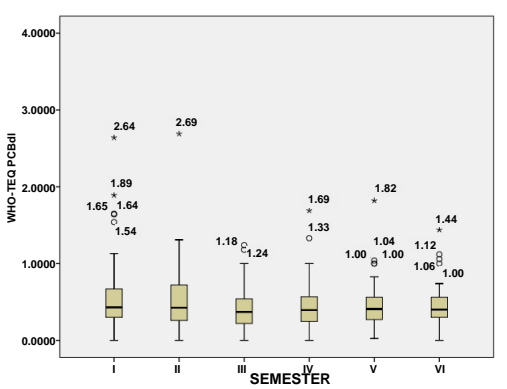

(c)

Figure 1. (a)-(c) Box plots summarizing the global data from 2011-2014 monitoring plan on milk from Campania Region. (a) PCDD/F; (b) Sum PCDD/F-DL-PCB; (c) DL-PCB.
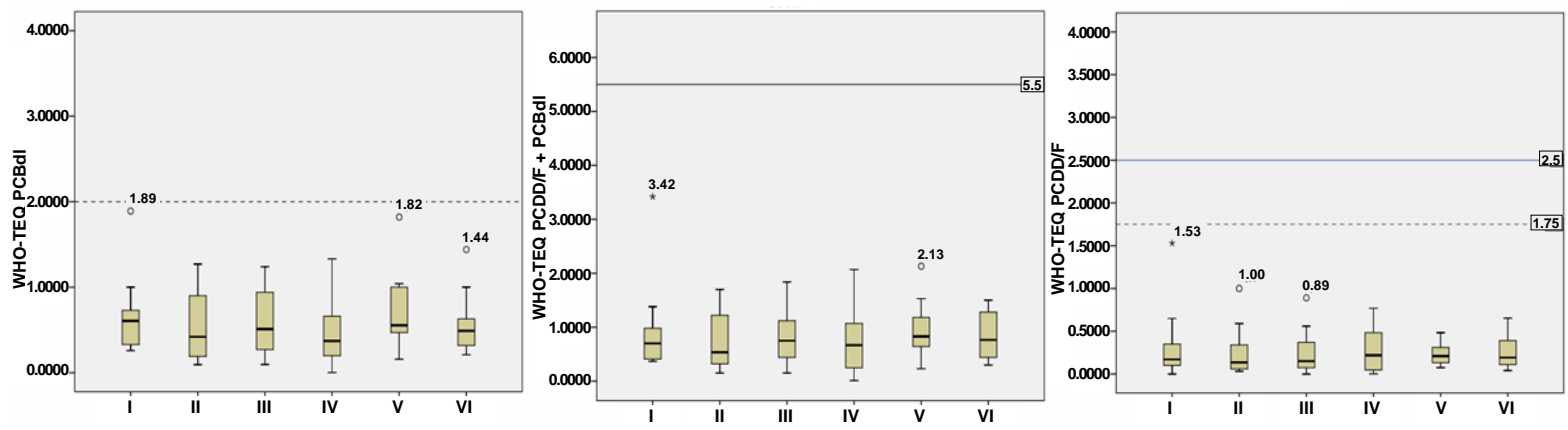

Figure 2. Box plots summarizing the global data from 2011-2014 monitoring plan on bovine milk from Campania Region.
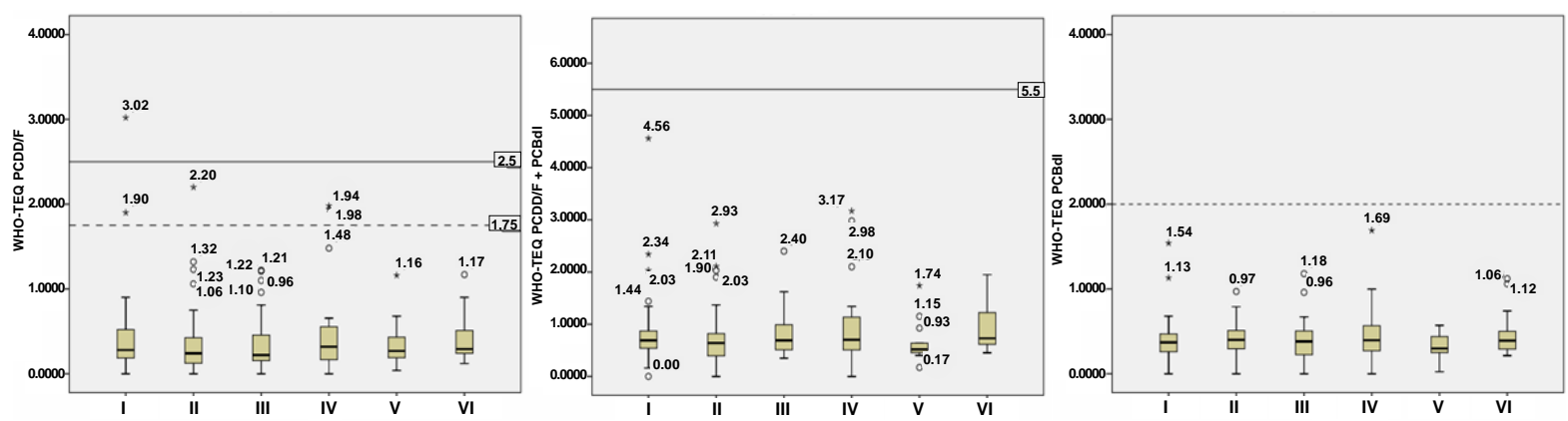

Figure 3. Box plots summarizing the global data from 2011-2014 monitoring plan on buffalo milk from Campania Region. 

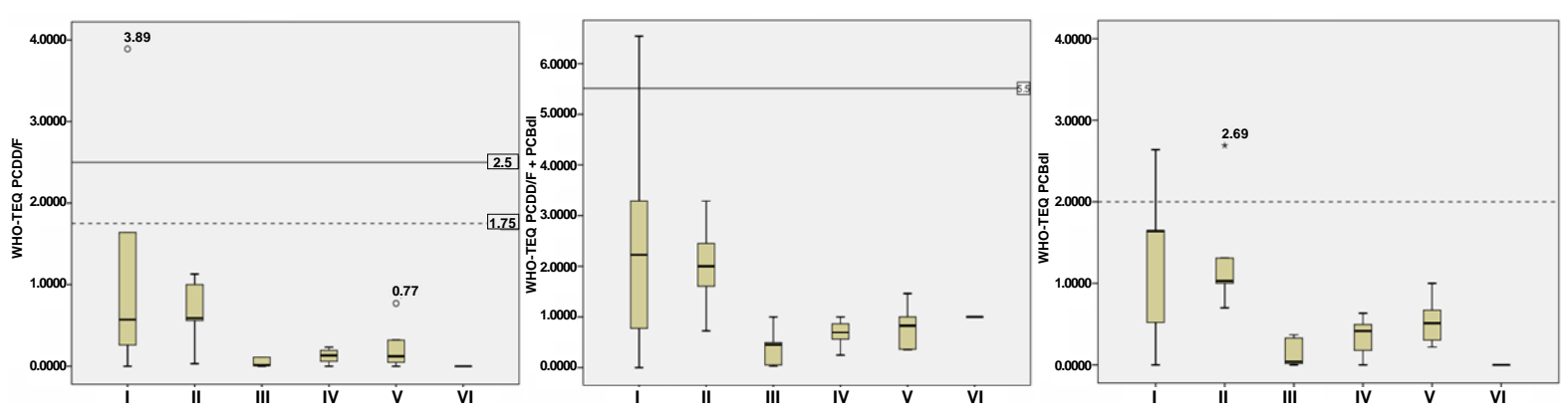

Figure 4. Box plots summarizing the global data from 2011-2014 monitoring plan on ovine milk from Campania Region.

Table 1. Contamination data on milk from Campania Region in the period 2008-2014.

\begin{tabular}{|c|c|c|c|c|c|c|c|}
\hline & \multirow{2}{*}{$\begin{array}{l}\text { Median values expressed } \\
\text { as WHO-TEQ pg/g fat }\end{array}$} & \multicolumn{3}{|c|}{ Surveillance plan 2007} & \multicolumn{3}{|c|}{ Monitoring plan 2011-2014 } \\
\hline & & $\begin{array}{c}2008 \\
(\text { n. 113) }\end{array}$ & $\begin{array}{l}2009 \\
(n .85)\end{array}$ & $\begin{array}{c}2010 \\
(n .58)\end{array}$ & $\begin{array}{l}\text { I semester } \\
\quad(\text { n. 46) }\end{array}$ & $\begin{array}{l}\text { III semester } \\
\quad(\text { n. } 46)\end{array}$ & $\begin{array}{l}\text { VI semester } \\
\quad(n .32)\end{array}$ \\
\hline \multirow[t]{3}{*}{ Buffalo } & $P C D D / F s$ & 0.75 & 1.36 & 0.55 & 0.29 & 0.23 & 0.29 \\
\hline & $D L-P C B s$ & 0.66 & 1.02 & 0.53 & 0.36 & 0.38 & 0.39 \\
\hline & $S U M(P C D D / F+D L-P C B)$ & 1.54 & 2.36 & 1.08 & 0.65 & 0.59 & 0.73 \\
\hline \multirow[t]{3}{*}{ Bovine } & $P C D D / F s$ & 0.48 & 0.37 & 0.40 & 0.17 & 0.16 & 0.19 \\
\hline & $D L-P C B s$ & 0.58 & 0.48 & 0.50 & 0.56 & 0.51 & 0.49 \\
\hline & $S U M(P C D D / F+D L-P C B)$ & 1.14 & 1.01 & 0.83 & 0.70 & 0.73 & 0.77 \\
\hline \multirow[t]{3}{*}{ Sheep } & $P C D D / F s$ & 0.50 & 0.52 & 0.53 & 1.11 & 0.06 & - \\
\hline & $D L-P C B s$ & 0.59 & 0.85 & 0.64 & 1.65 & 0.19 & - \\
\hline & $S U M(P C D D / F+D L-P C B)$ & 1.09 & 1.47 & 1.17 & 2.75 & 0.25 & - \\
\hline
\end{tabular}

the presence of a general background contamination level of milk from Campania in the period 2008-2014, probably due to the "good practices" of storage of feed intended for milk producing farms, implemented after the dioxin crisis of 2008.

\section{Conclusion}

The implementation of good farming practices suggested during the sanitary emergencies of the past early years made safer the milk and dairy production in Campania, for the presence of PCDD/Fs and DL-PCBs, as evidenced in the present monitoring study. On the other hand, the prosecution of extraordinary monitoring plans by Sanitary Authorities is desirable because of the critical still existing in Campania Region.

\section{Acknowledgements}

Special thanks to Dr. Roberta Brunetti and to the staff of Osservatorio Regionale per la Sicurezza Alimentare (ORSA).

\section{References}

[1] Esposito, M., Serpe, F.P., Cavallo, S., Pellicanò, R., Gallo, P., Colarusso, G., D’Ambrosio, R., Baldi, L., Iovane, G. and Serpe, L. (2010) A Survey of Dioxins (PCDDs and PCDFs) and Dioxin-Like PCBs in Sheep and Goat Milk from Campania, Italy. Food Additives and Contaminants Part B, 3, 58-63. http://dx.doi.org/10.1080/19440040903527350

[2] Esposito, M., Serpe, F.P., Neugebauer, F., Cavallo, S., Gallo, P., Colarusso, G., Baldi, L., Iovane, G. and Serpe, L. (2010) Contamination Levels and Congener Distribution of PCDDs, PCDFs and Dioxin-Like PCBs in Buffalo’s Milk from Caserta Province (Italy). Chemosphere, 79, 341-348. http://dx.doi.org/10.1016/j.chemosphere.2010.01.025 
[3] Esposito, M., Cavallo, S., Serpe, F.P., D’Ambrosio, R., Gallo, P., Colarusso, G., Pellicanò, R., Baldi, L., Guarino, A. and Serpe, L. (2009) Levels and Congener Profiles of Polychlorinated Dibenzo-p-Dioxins, Polychlorinated Dibenzofurans and Dioxin-Like Polychlorinated Biphenyls in Cow's Milk Collected in Campania, Italy. Chemosphere, 77, 1212-1216. http://dx.doi.org/10.1016/j.chemosphere.2009.09.011

[4] US Environmental Protection Agency (USEPA) (1994) USEPA Method 1613. Tetra- through Octa-Chlorinated Dioxins and Furans by Isotope Dilution HRGC/HRMS. October. USEPA Office of Water Engineering and Analysis Division, Washington DC.

[5] Van den Berg, M., Birnbaum, L.S., Denison, M., De Vito, M., Farland, W., Feeley, M., Fiedler, H., Hakansson, H., Hanberg, A., Haws, L., Rose, M., Safe, S., Schrenk, D., Tohyama, C., Tritscher, A., Tuomisto, J., Tysklind, M., Walker, N. and Peterson, R.E. (2006) The 2005 World Health Organization Re-Evaluation of Human and Mammalian Toxic Equivalency Factors for Dioxins and Dioxin-Like Compounds. Toxicological Sciences, 93, 223-241. http://dx.doi.org/10.1093/toxsci/kfl055 